\title{
E-investigación: una introducción para principiantes (y escépticos) a las fuentes de ciencia política disponibles en la web ${ }^{1}$
}

\author{
Mauro Calise y Rosanna de Rosa
}

\begin{abstract}
Algunas veces me pregunto si no somos como los dinosaurios, mirando hacia el cielo el asteroide que se acerca, y pensando si afectará en algo nuestro futuro. ${ }^{1}$
\end{abstract}

A lo largo de dos milenios y medio de progreso y difusión gloriosos, el texto ha sufrido de dos grandes limitaciones: acceso y acumulación. A pesar de los grandes avances alcanzados al ir desde los antiguos papiros hasta los modernos libros rústicos, el texto escrito siempre ha sido voluminoso; la cantidad de cultura disponible para los lectores individuales, ha tenido serias limitaciones debido a restricciones de espacio. Hoy en día, sin embargo, las limitaciones de acceso y acumulación están desapareciendo rápidamente en el nuevo ambiente de lectura creado por la "World Wide Web". En una pantalla tenemos ahora disponible de manera inmediata el mundo entero de la publicación electrónica, y éste está rápidamente sobrepasando a la totalidad del texto escrito o impreso en los veinticinco siglos anteriores.

Mediante el uso de cualquiera de los más recientes y poderosos motores de búsqueda de última generación, ésta biblioteca universal (sin paredes) puede ser hojeada a la velocidad de la luz. Estas nuevas Alejandrías electrónicas están haciendo que libros, artículos, documentos oficiales y reportes de investigación estén al alcance de un creciente número de sectores de la población global. Esto es una gran oportunidad para el progreso intelectual masivo, comparable sólo con el nacimiento y difusión del libro impreso. Al mismo tiempo, el nuevo formato electrónico del conocimiento académico está redefiniendo la investigación, la escritura y el pensamiento de maneras que hasta ahora apenas comenzamos a entender. El ámbito de las publicaciones académicas está experimentando una gran transformación, con la autoría (santuario de la comunicación científica) enfrentando los retos planteados por el libre acceso y la cultura abierta (Les-

1 Este documento fue publicado originalmente en International Political Science Review, volume 29, number 5 , november 2008. (C) 2008, International Political Science Review. Reprinted by permission of SAGE. 
sig, 2004; Willinsky, 2005). Aunque la muerte del libro como el baluarte del conocimiento tradicional puede ser una de esas predicciones apocalípticas que jamás ocurrirán, la circulación de ideas está, sin embargo, adoptando formas y canales sin precedentes.

Ante el ímpetu de semejantes cambios, la Ciencia Política (CP) demuestra poco o ningún conocimiento de lo que implica la revolución de Internet sobre los prospectos y las tendencias de la disciplina. A pesar de que la gran mayoría de practicantes de la ciencia política en su trabajo intelectual diario hace uso intensivo de todo tipo de recursos disponibles en Internet, la especulación sobre este tema es muy limitada. En un simposio sobre los cambios más grandes y duraderos en la disciplina, organizado por los doce presidentes más recientes de la "American Political Science Association (APSA)", sólo hubo una pequeña mención de la "web". ${ }^{2}$ Adicionalmente, al hojear todas las revistas académicas y profesionales importantes de la disciplina, se encuentran pocos artículos que monitoreen o debatan los cambios electrónicos en el ambiente investigativo. La situación es aún más sorprendente si se considera el extraordinario crecimiento de una nueva y vibrante comunidad epistémica, que está redefiniendo con entusiasmo la ciencia y el conocimiento a la luz de los logros de la web.

El objetivo de este artículo es contribuir a llenar este vacío. Presentaremos un breve bosquejo (ajustado principalmente para los neófitos del ciberespacio) sobre algunos de los mejores recursos disponibles para la investigación académica. Nos enfocaremos en la ciencia política apoyándonos en nuestra experiencia como editores del portal IPSA, página web del "International Political Science Association", la cual está especializada en seleccionar y reseñar los mejores e-bubs de nuestra disciplina. ${ }^{3}$ Sin embargo, al aventurarnos en el ciberespacio de la ciencia política, trataremos de ofrecer una compresión más general de las principales tendencias que están impactando la galaxia del internet. Por más que estemos tentados a enfocarnos en nuestro pequeño mundo de la ciencia política, tenemos que ser conscientes de que él proviene de un sistema más grande del que también forma parte.

\section{Integración}

Basándonos en la estructura de clasificación del portal IPSA, subdividimos nuestro repaso en cuatro bloques principales: catálogos, textos, bases de datos y redes abiertas. Estos bloques reflejan la rutina diaria del trabajo intelectual: hojear el catálogo de una biblioteca para buscar información y todo tipo de referencias bibliográficas; leer varios tipos de textos, desde periódicos hasta ensayos y libros; acceder a bases de datos numéricas o textuales, desde colecciones de documentos oficiales hasta archivos estadísticos; y conectarse con gente interesada en nuestro tema de investigación para discutirlo con ellos. El mantener estos cuatro bloques 
separados en nuestra clasificación ciertamente ayudará a los lectores a orientarse a través de las tradicionales categorías y hábitos. Representa también, en un alto grado, el mejor método para delinear un panorama claro de la bonanza electrónica a nuestro alcance con solo un click. Sin embargo, la tendencia dominante en el ciberespacio consiste en romper las divisiones y hacer converger las varias corrientes de información cultural. La fuerza crucial que está barriendo la web en lo que respecta a las fuentes electrónicas es la integración: integración entre varios formatos y canales, y entre autores y usuarios.

El mejor ejemplo de esta tendencia es Google, el motor de búsqueda que en pocos años ha impuesto nuevos estándares y redefinido la lógica para navegar la web. Cuando se está "googliando", las búsquedas no están limitadas a lugares o formatos específicos, al contrario, cubren a todo el ciberespacio accesible a los algoritmos indexadores de Google. Esta revolución da cuenta de su inmenso poder para descargar información y de su inmensa popularidad entre casi todos los usuarios de Internet (Vise y Malseed, 2005). También ha contribuido de manera importante a establecer, especialmente entre las generaciones jóvenes, la actitud cultural dominante que considera que la información existe y que puede ser accedida sin limitaciones de espacio, lugar y mucho menos de tiempo (Meyrowitz, 1985). Según los estándares de Google, hoy en día nuestra expectativa es buscar un título o un autor, encontrar todos los hipervínculos a los textos relacionados (ya sea artículos, libros o sólo las transcripciones de una conferencia o un video), leer libremente este material e imprimirlo si es posible, acceder a las fuentes primarias del texto (estadísticas, reportes de encuestas, publicaciones gubernamentales, etc.), hojear Wikipedia y eventualmente crear un chat o un foro para compartir nuestras opiniones con cualquiera que se interese.

Mientras que este es un típico ambiente Google, el cual hoy en día la mayoría de jóvenes da por sentado ${ }^{4}$, no es la situación que encontramos cuando navegamos a través del dominio especializado de una disciplina, o quizás deberíamos decir, no lo es todavía. La integración se está extendiendo hacia toda sub-galaxia cultural, aunque dependiendo de la barreras que tenga que superar lo hace a distintas velocidades. Podemos distinguir tres tipos de barreras que desaceleran la integración.

La primera y más importante es una vieja conocida de las ciencias sociales: la división entre lo público y lo privado. En los últimos años, lo "público" ha ganado en la web un territorio tan extenso como se pueda imaginar. Está en el núcleo mismo de la visión general sobre el internet, con la libre circulación y el libre acceso como sus dos principios básicos. Esto ha generado la expectativa creciente de que todo lo que esté en la web debería ser del dominio público, lo que se ha vuelto más factible gracias al progreso técnico que ha hecho que la 
digitalización y circulación de todo tipo de material esté disponible a todo procesador de escritorio. En lo que respecta al mercado académico, todavía persisten dos limitaciones al acceso público total: los derechos de autor para libros y las leyes de propiedad corporativa para las revistas. En ambos casos, la violación de estas limitaciones se está haciendo cada vez más generalizada. Los libros anteriores a la protección de los derechos de autor están siendo digitalizados por millones y los usuarios gozan de acceso gratuito y libre a ellos. Muchos de los libros actuales pueden ser leídos (por partes o enteros) sin costo alguno, a través de una variedad de canales, desde las páginas web de los autores hasta como resultado de políticas especiales de mercadeo de editoriales individuales. Es más complicado acceder a las revistas fuera del tradicional proceso de suscripción institucional o individual; esto representa un problema si se considera que hoy en día las revistas constituyen una porción muy importante de acceso académico a fuentes secundarias. ${ }^{5}$ Sin embargo, el movimiento del libre acceso está ganado (algún) ímpetu a través de su propia contribución vía el creciente número de revistas con libre acceso en línea, pero también gracias a algunas inesperadas contribuciones de las "tres grandes" editoriales de revistas. ${ }^{6}$ Debido a fuertes críticas a su control oligopólico, uno de los más grandes conglomerados de la publicación está ofreciendo acceso gratuito en la web a algunas secciones de su colección electrónica. ${ }^{7}$

La segunda barrera es la división y diferencia entre la web superficial y la web profunda, barrera que se extiende a través de los límites entre los dominios públicos y los dominios privados. En el comienzo todo era "profundo" y la información estaba encerrada en los archivos privados. Los datos electrónicos eran guardados en servidores separados, de acuerdo con métodos diferentes de indexación y de categorización, así sea la nómina de una compañía o la lista de suscriptores de una revista. Estos datos sólo podían ser extraídos en el lugar físico, por aquellos con el derecho legal para hacerlo y con la fórmula técnica para adentrarse en el sistema. Luego llegó Internet y todo tipo de material comenzó a salir a la luz a través de vínculos e hipertextos que merodeaban por todo el ciberespacio. Inicialmente parecía un caos, siendo la sobrecarga de información la maldición de los cibernautas primigenios.

Pronto, sin embargo, algo de orden se (re)introdujo gracias a los poderosos motores de búsqueda. Cualquier cosa publicada en Internet podía ser encontrada y accedida instantáneamente con la aplicación de los algoritmos y "spiders" de Yahoo y Google. La cantidad de recursos disponible con un clic del ratón fue una bonanza tan sin precedentes que pareció como si cualquier información en cualquier lugar del mundo perteneciera ahora a nuestro procesador. Sin embargo, apenas estábamos y apenas estamos empezando a escudriñar la superficie 
de la web: "gran parte de la web todavía está sin catalogar... Muchas bases de datos y otros sitios web de gran interés para el académico y con información de alta calidad, están dentro de lo profundo de la web, incluyendo aquellos que no cobran por su contenido" (Selcher, 2005:182). Aunque es una cifra tentativa, se estima que la superficie de la web llega a ser un poco más del uno por ciento de todos los terabytes de información ocultos en los archivos verticales, que organizan y dirigen la mayor parte de nuestra vida diaria (Bergman, 2001). La web profunda sigue siendo un mundo en sí mismo, inaccesible al poder de indexación automática de Google.

Sin embargo, las excepciones están aumentando y marcando tendencias. El camino hacia la integración entre la web superficial y la profunda puede ser directo o indirecto. La mayoría de archivos del gobierno, catálogos y colecciones universitarias mantienen sus puertas abiertas a cualquier visitante de la web. Adicionalmente, en muchos casos la interfaz de búsqueda está abandonando la compleja sintaxis y las particiones de las bases de datos especializadas y está adoptando la lógica "busca mientras hablas" (SAYS), popularizada por Google. Estas medidas todavía no son suficientes para crear el fluido ambiente de investigación al cual nos hemos acostumbrado al usar la superficie de la web, pero sí contribuyen a una navegación más sencilla y amigable para el usuario de una galaxia extraordinaria y rica, repositorio de información que antes fue inaccesible. La integración directa es un logro más complicado. Técnicamente la integración directa implica que un motor de búsqueda con todas sus cookies y spiders simule varios trillones de búsquedas como las formuladas por humanos para extraer toda la información de cada archivo y hacerla fácilmente accesible a cualquier pedido estándar de la web superficial, una operación que tiene que ser repetida incesantemente para mantener la información constantemente actualizada. Nuevos empresarios en el mundo de la alta tecnología han estado tratando de desarrollar una solución para franquear esta última pared digital; el reciente progreso de Yahoo parece que está yendo en la dirección correcta (Wright, 2004).

Además de encontrar la tecnología de punta para unir las partes profundas y superficiales de la web, se requiere de una buena cantidad de ingeniería burocrática detallada. El minimizar dispendiosos procesos burocráticos juega un papel tan importante como el diseñar chips electrónicos, cuando el objetivo es hacer que archivos separados sean parte de una misma plataforma digital. La última barrera pero no por ello la menos importante es cultural y lingüística. En el mundo contemporáneo de la comunicación global no debería causar sorpresa el éxito de la web al adoptar al inglés como lengua franca y hacer que todo tipo de esperantos fracasen, esto se debe a la ventaja estratégica de las corporaciones norteamericanas en el ambiente de la Tecnología de Comunicación 
e Información Global (ICT), junto con el tamaño del mercado estadounidense de internet. Sin embargo, esta integración es desacelerada cada vez que se tiene que lidiar con recursos dentro un contexto específico. Comprar música a través de Internet en inglés es fácil porque esta refleja, en alto grado, lo que es escuchado en la mayoría de países del mundo. Sin embargo, leer un libro francés requiere capacidades lingüísticas propias del mundo francófono, sin mencionar la miríada de lenguajes que identifican a naciones y grupos étnicos mucho más pequeños (Laponce, 2001). De esta manera el riesgo que se corre al digitalizar y dar acceso libre al patrimonio cultural del mundo, es que puede permearse de favoritismo anglosajón, lo que es otro poderoso factor para la diseminación de la hegemonía estadounidense sobre el accionar científico actual. Esto puede que no represente un gran problema para aquellos que trabajan en disciplinas que han sido integradas en un sistema de comunicación académica basado en un solo lenguaje, como desde hace tiempo ha sido el caso de la mayoría de las ciencias naturales, pero sí representa un problema para la mayoría de investigaciones en el área de las humanidades, especialmente cuando se está trabajando con repositorios históricos. En la introducción al manifiesto más franco sobre la preservación de la diversidad cultural (Jeanneney, 2007) se arguye que "el problema no es la totalidad de la obra, sino también el contexto cultural y la lengua en que la obra fue concebida, escrita, publicada, leída, comprendida y preservada. La información tiene muchos contextos y conforma su significado completo dentro de estos. La manera como un motor de búsqueda seleccione, organice y presente la información puede destruir el contexto o distorsionarlo invisiblemente" (Wilson, 2007: xi). Sólo se puede tener la esperanza de que el riesgo de convertirse en una "colonia electrónica" motive a los gobiernos y a las organizaciones internacionales a incrementar sus esfuerzos e inversiones para asumir los retos de la web global, como es ya el caso con varios proyectos destacados que estaremos analizando en la siguiente sección.

\section{Pila (Stack) electrónica}

Las disciplinas del mundo de las ciencias sociales, con excepción de la ciencia política, han puesto mayor atención a los cambios engendrados por el nuevo ambiente de la web en la teoría y en la investigación empírica. Los estudios literarios han sido los pioneros en el debate sobre las implicaciones epistemológicas del trabajo académico que, cada vez en mayor grado, se está haciendo mediante los patrones asociativos de los vínculos hipertextuales (Bolter, 2001; Landoe, 1997, 2006). La sociología ha estado ofreciendo ideas frescas sobre el potencial enorme de la interconexión de las comunidades investigativas, mediante el uso de canales alejados de los tradicionales del mundo académico. (Bohlin, 2004; Castells, 1996, 2000; DiMaggio et al., 2001). La historia ha sido la primera en 
aprovecharse de la ilimitada expansión de fuentes disponibles a cada procesador (Cohen and Rosenzweig2, 006; Rosenzweig2, 001). La ciencia política, con algunas pocas pero relevantes excepciones (Burnham et al., 2008; Choucri, 2000; Giles, 1996; Kaase, 2000; Nentwich, 2008), parecer estar menos interesada en definir los prospectos y la implicación de la investigación electrónica.

Lo anterior no quiere decir que el uso de los medios electrónicos no esté muy difundido y que no sea masivo. Sólo mirar las estadísticas de JSTOR, con un promedio mensual de 50 millones de accesos, demuestra que gran parte de las investigaciones realizadas en publicaciones que ya salieron de circulación se está haciendo a través de la web. Más aún, muchos en la profesión comparten la experiencia de Arendt Lijphart: "la disponibilidad de todo tipo de información para la investigación de los sistemas electorales e instituciones políticas ha mejorado sustancialmente" durante los últimos veinte años. ${ }^{8}$ Sin embargo, es difícil evaluar cuan conscientes son los politólogos de los extraordinarios recursos que finalmente les ofrece la web. Esta afirmación es más certera cuando nos desplazamos desde el uso de unos pocos archivos claves para descargar y buscar información, hasta un entendimiento más sistemático de la complejidad del ambiente de la web. Esta tarea se hace más difícil por el hecho de que la web es por definición, una frontera en constante movimiento. Cada día se añaden nuevas páginas web y las viejas están siendo modificadas continuamente en contenido, acceso e interfaz. Este gran crecimiento se puede ver al comparar esbozos de las viejas fuentes de ciencia política (Deibert, 1998; Spang, 1997; Walker, 1998), con las fuentes más recientes (Quinn, 2007; Selcher, 2005).

Para llevar un registro lo más preciso posible del crecimiento del ciberespacio investigativo, IPSA ha lanzado el portal IPSA, un punto de entrada a una selección de las páginas web más valiosas para los politólogos. ${ }^{9}$ De esta manera IPSA se une a un número de iniciativas innovadoras que sirven de portal y guía a través del laberinto de fuentes en internet, como "The Librarians Index to the Internet" ${ }^{10}$ o "Intute: Social Sciences." A través de estos portales se puede disfrutar la complejidad del ambiente académico en la web, mientras se encuentra una guía autorizada para finalizar búsquedas en una agenda de investigación personal.

Los sitios web que reseñamos en este artículo, por ende, no pueden sustituir a la extrema riqueza y variedad de los recursos electrónicos disponibles. Sin embargo, con los ojos puestos sobre las diferentes actitudes y destrezas en nuestra profesión, esperamos que sirvan de ejemplo para ilustrar las nuevas oportunidades que está ofreciendo Internet en los diversos segmentos de nuestra rutina de investigación. El uso de recursos electrónicos depende en un muy alto grado de una mezcla de entrenamiento intelectual y técnico, así como del tiempo que estemos dispuestos a dedicarle a algunas tareas que a menudo 
resultan más bien complejas. Las diferencias se hacen cada vez más patentes cuando nos adentramos en los sofisticados ambientes cooperativos de investigación electrónica, con un cambio en el balance entre los académicos júnior y los séniores. De hecho los junior "carecen de la red interpersonal que soporta la búsqueda de información y del complejo conocimiento heurístico que los séniores tienen de la literatura. Este grupo (los júniores) depende mucho más de los catálogos, índices, resúmenes y motores de búsqueda para encontrar información sobre algún tema de interés" (Borgrnann, 2003: 113). Algo similar ocurre en los patrones de aprendizaje de la comunidad estudiantil. (Bond et al., 2006; Robinson and Schlegl, 2005).

Por más tentados que estemos de considerar al ciberespacio como una galaxia uniforme, ésta asume diferentes formas y direcciones dependiendo del uso que cada uno le dé a su procesador.

\section{Catálogos}

El catálogo bibliotecario es el lugar en donde una investigación comienza y en los últimos años es el lugar en donde el proceso de integración quizás más ha crecido. Las primeras décadas de la automatización bibliotecaria padecieron varios obstáculos: repositorios y archivos estaban ubicados en distintos lugares del campus universitario, con sistemas de indexación frecuentemente incompatibles, y software propietario no estándar para el manejo de datos, diseñado según las necesidades de cada institución cultural. Luego, con la unión de los sistemas de automatización de índices y los nuevos ICTs -- particularmente la penetración de Internet en el campo académico --, se abrieron nuevas oportunidades para el desarrollo de servicios de extracción de información. La estandarización de los metadatos y su convergencia gradual unida a su centralización dentro de catálogos unificados, la difusión de las bases de datos en línea y la aplicación de una nueva interfaz para buscar información (de una interfaz textual a una gráfica), contribuyeron al desarrollo de los servicios en línea de navegación para los sistemas de Catálogos de Acceso Público En Línea (On-line Public Access Catalogue) (OPAC), que cubren tanto bibliotecas asociadas como individuales (Besser, 2002). La aurora del nuevo siglo fue testigo de la integración de catálogos al nivel universitario, estatal y nacional, basada en la racionalización de archivos y nuevas estrategias para la optimización de la búsqueda en-línea, con la convergencia clara de formatos diversos.

Las innovaciones tecnológicas más recientes se enfocan en la administración de sistemas cooperativos dirigidos a la integración de catálogos híbridos, por ejemplo, unir las bases de datos de los museos con sus archivos históricos, 
o el escaneo de manuscritos raros y la visión del conjunto de datos específicos. Esta tendencia ha llevado a: la creación de servicios de búsqueda unificados e inter-bibliotecarios, la creación de un nivel de indexación más profundo para libros, revista y reportes científicos, y al mejoramiento de las opciones de búsqueda primarias mediante el uso de texto completo y de preferencias avanzadas de búsqueda. ${ }^{12}$ El servicio básico provisto por la mayoría de las bibliotecas es ofrecer un acceso público en línea a sus recursos bibliográficos, ahora expandido con una serie de opciones más avanzadas. Este servicio básico por lo general es gratuito, permitiendo así a los usuarios de Internet acceso a una cantidad sin precedentes de información científica. En esencia cada OPAC representa una colección relacionada de archivos y de registros indexados, con una interfaz de búsqueda y con una estructura consistente que es compartida por todas las bibliotecas inscritas. El marco para los registros sufrió un proceso de estandarización internacional que llevó al diseño de un catálogo electrónico basado en la lógica de la tarjeta bibliográfica, como fue establecida por la "International Standard Bibliographic Description (ISBD)". Las OPAC de hoy proveen: búsquedas en más de un catálogo (cross-searching), varias opciones para refinar los resultados de la búsqueda, personalización de la interfaz, alertas de email, y actualizaciones. Las OPAC más avanzadas permiten el uso combinado de Refwork, EndNote y otros programas para el uso de citas, y optimizan el proceso de búsqueda al facilitar la fácil inserción y edición de campos de referencias bibliográficas.

No hay mejor lugar que la Biblioteca del Congreso de los Estados Unidos ${ }^{13}$ (US Library of Congress (LoC)) para obtener una visión completa sobre la compleja transformación de la biblioteca de un espacio físico a un espacio virtual. Hoy en día la LoC tiene opciones en-línea para la búsqueda de 14 millones de registros. ${ }^{14}$ Prácticamente ofrece el más completo “¿Quién es Quién?” de la producción anglo americana, al lado de una muy completa cobertura de libros en otros idiomas. El acceso gratuito y a nivel mundial a un listado preciso y exhaustivo de la producción académica es un logro extraordinario, inclusive con la competencia internacional que inspira, así la gran mayoría de académicos o estudiantes graduados que trabajan en cualquier biblioteca de los EEUU lo den por sentado. La Biblioteca Europea ${ }^{15}$ (The European Library), un proyecto de la Conferencia de Bibliotecarios Nacionales Europeos (Conference of European National Librarians), reúne a 48 bibliotecas nacionales, y da acceso unificado a todos sus catálogos - lo que constituye una magnífica oportunidad para experimentar la belleza y las espinas del multiculturalismo. Al buscar un libro en todos los países europeos, los usuarios pueden tener un claro panorama de la variedad regional - especialmente porque la búsqueda a través de las diferentes naciones es lenta y los números y nombres van apareciendo lentamente, uno después del otro, al contrario de los nanosegundos que se toma Google. Para 
hacer que los resultados sean más exactos hay un teclado virtual que hace que los caracteres y letras acentuadas de distintos alfabetos estén disponibles (por ejemplo, cirílico o griego) para buscar dentro de cada biblioteca nacional o en colecciones especiales.

La Biblioteca Europea y la LoC son dos prototipos sobresalientes de un proceso que ha gestado los mismos cambios en todas las grandes bibliotecas de investigación. ${ }^{16}$ Para el usuario en-línea, la información bibliográfica dejó de ser lo que diferencia un lugar del otro: una búsqueda virtual en Cornell o Harvard, seguramente llegaría a los mismos resultados. Que los libros estén disponibles enlínea es lo que cuenta. La digitalización de colecciones especiales y la adquisición de libros electrónicos es la nueva frontera en la cual los bibliotecarios invierten sus recursos humanos y financieros, con resultados variados y a velocidades diferentes (Brown et al. 2007).

\section{Libros y articulos}

El viaje a través de este material digital tiene dos vías principales. La primera opción es seguir la vía tradicional a través de una gran cantidad de material agrupado alrededor de un tema histórico, disciplinario o cultural. En este caso las bibliotecas han transformado en archivos electrónicos ${ }^{17}$ un conjunto más o menos grande de documentos que ya se encontraban guardados en colecciones separadas.

Veamos algunos ejemplos de los proyectos pioneros en esta área. El Proyecto de la Memoria Americana ${ }^{18}$ (American Memory Project) en el LoC, lanzado en 1990 y reimpulsado en 1994 con la fiebre de la web, guarda mapas, fotos, audio y video sobre la historia general y cultural de los EEUU. Las reproducciones y descripciones digitales de material raro (manuscritos, mapas, etc.) son también de libre acceso, mientras que algunos registros requieren afiliación institucional. Thomas, ${ }^{19}$ lanzado el mes de enero de 1995, es la entrada oficial a la información legislativa y el recurso primario sobre el congreso de los EE.UU desde su mandato 101avo. Contiene: legislación, registros del congreso, reportes de los comités, nominaciones presidenciales y tratados. Su servicio hace que textos completos de una gran cantidad de material en varios formatos sean accesibles gratuitamente, siendo su navegación de una gran facilidad a través de una interfaz con excelentes capacidades para sortear resultados y refinar búsquedas. Chronicling America ${ }^{20}$ (patrocinado por el National Endowment for the Humanities y por LoC como parte del National Digital Newspaper Program) permite a los usuarios buscar y leer periódicos de 1897 a 1910 y encontrar información sobre periódicos publicados en los Estados Unidos de América desde 1690 hasta el presente. 
The Making of America ${ }^{21}$ es un buen ejemplo del impacto que han tenido estos grandes proyectos digitales. The Making of America es una empresa conjunta de las universidades de Michigan y Cornell financiada por la fundación Andrew W. Mellon. Su labor es escanear fuentes primarias y secundarias de los años 1850 a 1876. Así una colección de material "que antes había sido usada intermitentemente por un campus de 40,000... está siendo accedida un millón de veces cada mes", por gente de todo el mundo (Courant. 2006: 8).

Usando el mismo computador mientras volamos sobre los Alpes, podemos navegar en Gallica, ${ }^{22}$ la sección digitalizada de la biblioteca nacional de Francia. Este repositorio en-línea, rápidamente creciente, ofrece acceso gratuito a más de 250,000 documentos y 100,000 imágenes, y provee una rara colección de trabajos franceses y francófonos, dossiers y revistas especiales de diferentes temas del siglo 14 al 20 (historia, leyes, economía, ciencia política, filosofía y literatura). La selección de diccionarios sobre la ciencia política y administrativa publicados desde el siglo 18,23 da una posibilidad extraordinaria de investigación histórica. El citar sólo cinco proyectos le hace una gran injusticia a la riqueza y a la variedad de lugares disponibles para navegar. En su cambio hacia el formato electrónico, la mayoría de las grandes bibliotecas mundiales ha adoptado el camino tradicional de las colecciones especiales pre-existentes o cotejadas para la digitalización. Esta es una oportunidad extraordinaria para cualquiera que tenga un tema específico y claro para investigar.

Desarrollándose rápidamente se encuentra la segunda y más reciente vía que busca hacer accesible en línea el más grande número de libros posible sin criterios específicos de selección -- el sueño de una biblioteca universal sin límites de acceso y uso. Este objetivo es perseguido por ejemplo por el "Proyecto de Un Millón de Libros"24 (One Million Books Proyect), cuya meta ha sido explícitamente enunciada como el "crear la biblioteca universal con una colección de un millón de libros para ser leídos y buscados libremente. Nuestra meta en diez años es que la colección crezca a los diez millones de libros. El resultado va a ser un recurso accesible a cualquier persona en el mundo sin importar su nacionalidad o su estado socioeconómico". ${ }^{25}$ Este proyecto internacional es administrado por la Universidad de Carnegie Mellon (Carnegie Mellon University) y es copatrocinado por grandes instituciones (entre ellas la US National Science Foundation), mientras la Universidad Zhejiang de China, el Instituto Indio de Ciencia (Indian Institute of Science) y la Biblioteca de Alejandría en Egipto (Library at Alexandria in Egypt) digitalizan una cantidad sin precedentes de volúmenes en 50 centros de escaneo alrededor del mundo: actualmente se han hecho disponibles en-línea 1.5 millones de libros. La colección incluye un gran número de libros raros en más de veinte lenguas. 
La meta general del proyecto es reducir la desigualdad presente en el acceso a los recursos culturales, al proteger y circular obras en otras lenguas y permitir que la gente en todo el mundo tenga acceso a obras difíciles de conseguir. Obras actuales del "mainstream" son, sin embargo, una parte relevante de la colección. La sección política incluye más de 20,000 libros, que incluyen una sustanciosa muestra de clásicos modernos como TheodoreJ. Lowi, David Easton y Giovanni Sartori.

El Proyecto del Millón de Libros (One Million Books Project) junto con otros como el Proyecto Gutenberg ${ }^{26}$ ya estaban bastante adelantados cuando Google entró en esta tendencia, trayendo consigo su conocimiento técnico y gran poder económico. Las acciones de Google prometían cambiar todo el panorama electrónico, inspiraban gran entusiasmo pero también preocupación ¿ंGoogle Book sería el advenimiento de la siempre profetizada pero siempre pospuesta era del fin del libro? (Hillesund, 2007; Kurzweil, 1992; Nunberg, 1993; Thompson, 2005). El estatus y tamaño de las universidades y editoriales que participan en el "Proyecto Libro de Google"27 (Google Book Project), indican que esta vez las barreras de la integración pueden ser superadas para el beneficio de la filosofía del libre acceso. Los elementos públicos y privados, profundos y superficiales, ingleses y no ingleses, están convergiendo en un gran esfuerzo para lograr que la mayor cantidad de libros posible sean de libre acceso desde cualquier rincón electrónico del mundo.

Entre todas las universidades que están escaneando sus repositorios con las innovadoras técnicas y fórmulas de Google, la Universidad de Michigan ha anunciado que ha hecho más de un millón de libros disponibles en-línea. Sin embargo, debido a las limitaciones impuestas por las leyes actuales de derechos de autor (por lo menos en los EEUU), sólo se permite descargar obras de dominio público o cuyo copyright haya caducado. La iniciativa de Google revela una importante diferencia disciplinaria sobre los beneficios que otorga el poder acceder a los libros digitalizados. Para todos los fines históricos, este cambio es revolucionario tanto en lo referente a la cantidad como a la calidad de la información disponible, sin mencionar la velocidad y la variedad de los usos posibles.

Google Books y páginas web similares van a ofrecer resultados limitados si se hace una búsqueda sobre literatura actual. ${ }^{28}$ Como advierte la página web de Google Books: "El objetivo de Google Books Search es ayudarle a descubrir nuevos libros y darle la información de dónde adquirirlos o pedirlos prestados, no es nuestro objetivo el que los pueda leer en-línea de principio al fin. Es como ir a una tienda de libros a hojear- con un giro Google". Esto suena, sin embargo, menos generoso que la realidad. El número de páginas disponibles de un 
libro actual varía dependiendo de las políticas y de las estrategias de mercadeo de las editoriales; sin embargo, partes sustanciales de estos pueden ser leídos en-línea-, labor fatigante pero reconfortante para aquellos que no tengan otra alternativa disponible en el momento. ${ }^{29} \mathrm{El}$ impedimento principal sigue siendo que "El costo de adquirir los permisos y encontrar los propietarios de los derechos para la vasta cantidad de material que ni es reciente ni tampoco muy viejo puede ser prohibitivo" (Courant, 2006: 4). Esta es la causa de la división principal en la búsqueda de fuentes secundarias, al hacer que los artículos en revistas sean más fáciles de extraer que los libros. Buscar en-línea un ensayo o artículo particular es realmente una historia muy diferente. En este caso la división entre lo público y lo privado hace todavía una diferencia. Aunque la mayoría de revistas existen en formato electrónico ${ }^{30}$, su acceso es limitado a los usuarios con alguna clase de privilegios - como ser suscriptor de una revista o archivo, o haber pagado-para-ver, o más comúnmente, como alguien con una afiliación institucional. Esta transformación electrónica ha traído sus consecuencias polémicas, principalmente: la concentración de la estructura de propiedad en el sector editorial y un fuerte aumento en los precios promedio de suscripción a revistas académicas. ${ }^{31} \mathrm{El}$ resultado es que muchas bibliotecas han sido forzadas a discontinuar su suscripción a publicaciones en papel, y en algunos casos han tomado acciones para combatir el oligopolio de los conglomerados editoriales electrónicos. $^{32}$

El lado positivo es que el ambiente de la revista digital ofrece un nivel de integración más alto. En la mayoría de los casos, la búsqueda de un artículo provee de acceso inmediato a su resumen junto con un vínculo directo al texto completo en formato $\mathrm{PDF}^{33} \mathrm{El}$ incremento en el uso de artículos versus libros en la comunidad académica, especialmente entre las generaciones jóvenes, recalca su importancia. El archivo más importante y más leído en esta categoría es JSTOR ${ }^{34}$ - un esfuerzo de la Fundación Mellón para ayudar a las bibliotecas al convertir a formato electrónico ediciones anteriores de revistas en papel, y para mejorar el acceso a este contenido (Schonfeld, 2003; Taylor, 2001). JSTOR, que opera como una organización sin ánimo de lucro, ofrece acceso a ediciones anteriores de revistas con fechas anteriores a la actual de mínimo entre tres y cinco años de diferencia. JSTOR cubre la distribución de más de 770 revistas científicas a través de 4000 instituciones alrededor del mundo y tiene un promedio de 50 millones de accesos cada mes y de 13 millones de artículos descargados los últimos tres meses. Navegar por la colección completa del American Political Science Review (así como por otras revistas importantes de la disciplina) es una experiencia intelectual sin precedentes. Junto con acceso inmediato y la habilidad de buscar a través de cualquier artículo, JSTOR ofrece una extensa presentación 
de los libros más relevantes en cualquier disciplina a través de preguntas en la extraordinariamente rica sección de reseñas de libros. JSTOR, como Google Books y LoC provee de un permalink $k^{35}$ como una oportunidad para personalizar la búsqueda aún más.

El Proyecto MUSE ${ }^{36}$ es en parte un complemento a JSTOR. Su enfoque son las ediciones recientes de las revistas, con una cobertura más amplia de las humanidades. Tiene casi 380 revistas de 40 editoriales académicas en las áreas de literatura y crítica, historia, las artes visuales e interpretativas, estudios culturales, educación, ciencia política, estudios de género, economía y otras disciplinas de las ciencias sociales. Mientras que el acceso al texto completo está restringido a las instituciones suscritas, el Proyecto MUSE permite la búsqueda libre en sus archivos y provee vínculos a ediciones pasadas en JSTOR cuando una revista está disponible en los dos lugares.

Aunque JSTOR y MUSE representan los recursos más distintivos en el campo de investigación académica en-línea, hay limitaciones de acceso que reflejan los costos de producción y mantenimiento de archivos, así como las restricciones financieras del sector de las editoriales. Estos factores pueden jugar un rol menor en los países que han llegado tarde al mundo de la comunicación científica, ya que ellos pueden aprovechar el ambiente de la web de una manera más libre.

The Scientific Electronic Library On-Line (SciELO), ${ }^{37}$ inaugurada en el 2002 como una metodología para la implementación de bibliotecas digitales para las revistas académicas, es un modelo exitoso para la publicación electrónica cooperativa de revistas académicas en Internet. Con el propósito de mejorar la producción y comunicación científica en los países de Latinoamérica y el Caribe, SciELO ofrece un acceso eficiente a su literatura científica. Sus servicios van desde la publicación en-línea de ediciones enteras de revistas científicas hasta la organización de bases de datos bibliográficas navegables de textos completos; desde la preservación de archivos electrónicos hasta la producción de indicadores estadísticos sobre el uso e impacto de la literatura científica hispanoamericana. Sus textos completos están enriquecidos con vínculos hipertextuales dinámicos hacia bases de datos nacionales e internacionales, y con vínculos directos a revistas electrónicas. El SciELO, que cubre muchas disciplinas, incluye alrededor de 540 revistas indexadas, más de 170,000 artículos y 3 millones de referencias, con más 70 de éstas revistas en el campo de las ciencias sociales. Uno de los activos clave que tiene SciELO es su Edición especial en Ingles de las Ciencias Sociales, hecha para el público internacional y diseñada para contrarrestar el hecho de que: 
Casi todo es publicado en español o portugués, lo cual disuade a muchos investigadores en países anglófonos y en países cuyo segundo lenguaje (especialmente en investigación) es el inglés. Esto no sólo impide el acceso y uso del material publicado en otras regiones sino también el descubrimiento de revistas dentro de los índices latinoamericanos, porque están, como es natural, también en español y portugués. (Babini and Smart, 2006:108).

Dentro del mundo no-anglófono deberíamos mencionar al proyecto Cairn. ${ }^{38}$ Inaugurado en el 2001 por un grupo de editoriales franceses con el apoyo de la Bibliotheque Nationale De France, se trata de un servicio de acceso y diseminación para las revistas francesas de las ciencias sociales y las humanidades, el cual ofrece varias opciones gratuitas de búsqueda. Finalmente pero no menos importantes, las tesis y disertaciones de doctorados tienen un creciente rol en el dominio de las fuentes secundarias. Con la regla de la entrega de las tesis en formato electrónico, varias iniciativas interuniversitarias han llevado a que exista un acceso fácil en internet a las disertaciones en todo el mundo. ProQuest Dissertation, la base de datos más grande de este tipo, puede ser accedida a través de suscripciones institucionales y contiene casi dos millones de títulos de los cuales 550,000 son de las ciencias sociales (65,000 a su vez pertenecen a la ciencia política). Dado el gran porcentaje de tesis que se están publicando como libros, esta área representa un importante segmento en la evolución electrónica de las fuentes secundarias al ofrecernos un acceso de gran calidad al mundo del cuasi-libro. Sin embargo, esto puede traer malas noticias para muchas facultades universitarias. De cara a una eventual crisis financiera, muchas bibliotecas "pueden pensarlo dos veces antes de gastar recursos escasos en libros cuando saben que se puede acceder con facilidad a las disertaciones originales" a través de un proveedor de internet (Thatcher, 2007: 131).

\section{Bancos de datos}

Si la integración de libros y artículos en un ambiente electrónico continuo y relativamente libre está transformando a la biblioteca tradicional en un punto de entrada del procesador, también está ocurriendo un cambio no menos revolucionario en la recolección de datos estadísticos y documentos oficiales. (Lazer and Mayer-Schönberger, 2007). Lo que alguna vez fue la dispendiosa labor de golpear en puertas burocráticas y de escudriñar archivadores cubiertos de polvo, se ha convertido en un acceso ágil en-línea a millones de documentos públicos. Esto no ha sido un logro fácil. ${ }^{39} \mathrm{El}$ esfuerzo hacia la digitalización y a la migración en-línea ha sido impedido por la vasta cantidad de datos involucrados, sus categorías específicas y extremadamente variadas, y por la necesidad 
de un gran apoyo financiero. A pesar de estas barreras los resultados han sido extraordinarios. El archivo Nacional de Australia ${ }^{40}$ provee acceso a más de 6 millones de registros y a 18 millones de imágenes (un 10 por ciento del total de su archivo), números que se multiplican varias veces si nos trasladamos a los EE.UU y a su National Archives and Record Administration (NARA). ${ }^{41}$ Desarrollado por la Electronic Records Archives Strategic Inciative, el principal repositorio de NARA es el Access Archival Database, (ARC) ${ }^{42}$ cuyo principal objetivo es ofrecer un acceso fácil a una inmensa cantidad de documentación e información. Hoy en día, la página web de NARA consiste de 85 millones de registros de texto completo y que, según NARA, son sólo un fragmento de los aproximadamente 10 billones de registros de su archivo material no disponible (todavía) en-línea. Dadas las extraordinarias cifras y la envergadura de sus posesiones históricas, una búsqueda en la base de datos de NARA es una actividad un poco compleja, con varias capas de datos y una amplia serie de campos que permiten al usuario definir sus propios "campos por defecto". Afortunadamente, la base de datos de NARA también provee a los usuarios caminos predefinidos basados en ayudas específicas de búsqueda y en datos orientativos. La base de datos de NARA también opera como un registro oficial y junto a la Goverment Printing Office $(\mathrm{GPO})^{43}$ indexa y publica la legislación federal, los documentos presidenciales, las regulaciones administrativas y los programas de las organizaciones federales. Esto quiere decir que los usuarios pueden acceder fácilmente a la recopilación semanal de documentos presidenciales, de los textos públicos del presidente, de las órdenes ejecutivas, etc.

Digital Vaults, ${ }^{44}$ diseñado para un público más generalizado, es una presentación multimedia e interactiva de los más importantes documentos e imágenes de la historia norteamericana. Tras haber sido inaugurado en febrero del 2008, ya ha sido nominado para el premio del 2008 al mejor sitio web de una institución cultural (2008 Best Cultural Institution Website Awards) y funge como punto de entrada para la vasta información de NARA. ${ }^{45}$

Al movernos de documentos oficiales a datos para la investigación empírica, el mejor punto de entrada es el Consorcio Interuniversitario para la Investigación Política y Social (ICPSR) ${ }^{46}$ (Inter-University Consortium for Political and Social Research) una red de 500 instituciones de todo el mundo. El ICPSR, único en profundidad y tamaño, fue establecido en 1962 en la Universidad de Michigan para la adquisición y preservación de información de las ciencias sociales. El ICPSR actúa como un repositorio de datos que recoge información de contenido histórico, grupos de información, e información sin filtrar derivada de proyectos de investigación, de cifras de censos y de registros administrativos, que puede ser usada para investigaciones futuras. Sus contenidos abarcan una amplia gama de disciplinas: ciencia política, sociología, demografía, economía, historia, educación 
y política pública. Provee material tanto cualitativo como cuantitativo para la investigación, por ejemplo, fuentes primarias y secundarias, cifras de censos, reportes de investigaciones etc. - un total de 500,000 archivos.

La Bibliografía de la Literatura relativa a los Datos (Bibliography of DataRelated Literature ${ }^{47}$ ) es otra función importante de búsqueda incluida dentro de los recursos instruccionales del ICPSR (ICPSR's Instructional Resources). Cubre las revistas del ICPSR a través de una base de datos que contiene más de 41,000 citas (resultados de un análisis de datos en la ICPSR) de trabajos conocidos publicados y sin publicar. Cada uno de sus registros está enriquecido con un detallado perfil de búsqueda y tiene la opción de descargar datos en bruto en distintos formatos (spss, ascii y sas), y procesarlos con una "herramienta de análisis" (de acceso restringido) o la opción de navegar por textos relacionados con el mismo tema.

Del lado europeo está el Consejo del Archivo Europeo de Datos de las Ciencias Sociales (Council of European Social Science Data Archive (CESSDA) ${ }^{48}$ ) que trabaja como una organización paraguas y ha operado desde 1970 para mejorar el acceso y distribución de datos. Tiene disponibles estudios sociológicos, estudios de elecciones, estudios longitudinales y datos de censos mediante una red de más de 20 organizaciones afiliadas a través de Europa, como el German Central Archive for Empirical Social Research $(\mathrm{ZA})^{49}$ y el French Centre de Données Socio-Politique (CDSP) ${ }^{50}$ localizado en Sciences Po en Paris. Entre las 50,000 colecciones de datos, también tiene conexiones con el European Social Survey ${ }^{51}$, el Eurobarometer ${ }^{52}$, el International Survey Program ${ }^{53}$ y el European Values Survey. ${ }^{54} \mathrm{El}$ portal del Council of European Social Sciences es fácil de navegar por tópicos, con una característica básica que permite a los usuarios localizar eficientemente cualquier ítem y vincularlo tanto a una descripción muy rica en texto como a la destinación final.

Un excelente ejemplo de cooperación entre naciones y entre instituciones es el Inter-Parliamentary Union (IPU) ${ }^{55}$ con más de 140 legislaturas que están participando en ella. Cubre áreas clave como la democracia representativa, la paz y la seguridad internacional, el desarrollo sostenible, los derechos humanos, las leyes humanitarias, la mujer en la política, en la educación, en la ciencia y en la cultura. ${ }^{56}$ Entre sus productos más valiosos están tres bases de datos. Parlit ${ }^{57}$ tiene documentación sobre los parlamentos nacionales, los sistemas electorales, la ley constitucional, la historia y la ciencia política, la ley parlamentaria y las elecciones legislativas alrededor del mundo, y abarca más de 7,000 libros y estudios y 30,000 artículos de 160 publicaciones periódicas.

Parline $^{58}$ y Women in Politics ${ }^{59}$ son las otras dos bases de datos (mantenidas al día) que pertenecen a la IPU. La primera provee información sobre cada cámara de parlamento, descripciones del sistema electoral, los resultados 
de las elecciones recientes, datos, gráficas e información de la presidencia y de la composición de cada cámara. La segunda provee referencias bibliográficas (incluidos resúmenes) de libros y artículos sobre la participación de la mujer en la política. Para cada base de datos están disponibles vínculos a los parlamentos del mundo y a páginas web con temas relacionados, de esta manera sirven como puntos de entrada para investigaciones de mayor profundidad.

\section{Redes abiertas}

Los archivos de libre acceso, apoyados en una nueva filosofía inspirada por la "economía de no-mercado" (Benkler, 2006), se están esparciendo a través del ciberespacio recogiendo contenidos científicos y "literatura gris" (documentos, memorias, pre-impresiones, disertaciones, y trabajos no revisados por pares). Los repositorios electrónicos de libre acceso, desarrollados en 1991 por Paul Ginsparg, (físico de la universidad de Cornell, conocido por haber desarrollado el archivo ArXiv.org e-print), ${ }^{60}$ han adquirido fuerza durante la última década, bajo el auspicio del Scholarly Publishing and Academic Resources Coalition (SPARC), una alianza de bibliotecas académicas y de investigación. ${ }^{61}$

Las instituciones bien establecidas tienen un rol muy importante en el universo de las actividades de libre acceso, ya sea por su capacidad individual o como redes de organizaciones, que cultivan la diseminación de material académico a través de los llamados repositorios institucionales, que son: "Infraestructuras de propósitos generales dentro del contexto de la cambiante práctica académica... [a] una respuesta a las preocupaciones sobre el existente sistema de publicación académica, los costos de las revistas, y el movimiento del libre acceso" (Lynch and Lippincort, 2005: 2). Los grandes centros de acceso libre incluyen al Social Science Research Network (SSRN), ${ }^{62}$ un proyecto apoyado por el Stanford Law School y por el European Corporate Governance Institute que involucra a un gran número de universidades y redes de investigación de las ciencias sociales y áreas afines (economía, derecho, seguro social y administración). La página web, a través de la biblioteca electrónica del SSRN, provee acceso a miles de artículos completos y resúmenes de revistas, editoriales e instituciones. También ofrece una base de datos de resúmenes con un número aproximado de 180,000 reseñas de estudios académicos en progreso y de estudios que todavía no han sido publicados, junto con una colección electrónica de más de 147,000 textos completos libremente descargables y en formato PDF.

En la otra orilla del Atlántico está Spire, ${ }^{63}$ el repositorio institucional de la National Foundation for Political Science. ${ }^{64}$ Spire posee una de las colecciones europeas de ciencias sociales más completas en ciencia política. ${ }^{65}$ Contiene una colección creciente de trabajos preliminares, reportes, pre-impresiones de revistas, revistas reseñadas y tesis digitales con texto completo. El London School 
of Economics (LSE) ${ }^{66}$ ofrece también una gran colección de material gratuito. Mediante el uso del LSE Research On-line ${ }^{67}$ se puede buscar y descargar artículos, trabajos preliminares, capítulos de libros, conferencias, etc. Se puede buscar u hojear por años, por departamentos, centros de investigación o grupos. Todos los ítems son descargables en formato PDF y son presentados en una estructura informativa de metadatos que posibilita el citar correctamente trabajos que todavía no se han publicado, como "Is Duverger's Law Based on a Mistake?" de Patrick Dunleavy et al. (2008).

Para una hojeada más clara sobre los recursos en ciencia política que se encuentran en archivos de libre acceso, se puede comenzar con el Political Research Online (PROL) ${ }^{68}$ un proyecto promovido por la American Political Science Association en cooperación con varias asociaciones nacionales e internacionales e institutos de investigación. ${ }^{69}$ PROL, patrocinado por la fundación Mellón, ha recopilado las actas de las conferencias y reuniones de las instituciones que participan en el proyecto desde el 2002 hasta el presente. La membrecía para el usuario es gratuita y sólo se requiere de un correo electrónico vigente para acceder a los resúmenes, referencias y textos completos. Actualmente dispone de más de 25,000 artículos en formato PDF, fáciles de buscar mediante palabras clave campos de contexto, autor y título. PROL es también una excelente herramienta para la promoción y circulación de información académica a escala mundial. Cada artículo viene con una opción de "más información" con vínculos directos a textos relacionados y referencias apropiadas en el estilo de Museos, Bibliotecas y del Consejo de Archivos (Archives Council) (MLA) y de la American Psychological Association (APA) permitiendo así una estrategia de investigación más profunda. Si visitamos la página web de $\mathrm{APSA}^{70}$ uno no debería perderse una joya $-\mathrm{y}$ un excelente ejemplo de lo que el libre acceso puede significar para obtener nuevos conocimientos sobre la disciplina. Aunque menos visible de lo que merece (la mejor ruta es Governance/President and Council/Past Presidents ${ }^{71}$ ) hay una página web con una lista de vínculos a los textos completos de los discursos de los presidentes de la asociación, quizás la presentación más vívida y completa de la evolución de la ciencia política a través de un siglo de debate teórico entre algunos de sus representantes más ilustres.

Quizá el panorama más completo del enteramente nuevo ambiente electrónico representado por los repositorios institucionales lo ofrece OAIster, ${ }^{72}$ un servicio de meta-búsqueda con base en la biblioteca de la Universidad de Michigan que cubre cientos de archivos de libre acceso a través de un único punto de entrada y de un portal con acceso a más de 15 millones de recursos académicos digitales, e incluye material gris, imágenes, texto, audio, películas y datos de más de 944 repositorios diferentes. Gracias al cosechar de metadatos, 
esta base de datos actúa como un punto de entrada para los archivos de libre acceso tal cual están indexados en el Open Archives Initiative Protocol for Metadata Harvesting. ${ }^{73}$

El creciente número de repositorios académicos atestigua el volumen de archivos que están siendo compartidos, editados y actualizados, y el uso más interactivo y libre de esta red de conocimiento. El libre acceso, además de la ayuda institucional que recibe, está siendo mejorado fuertemente por una red creciente de esfuerzos individuales, que constituyen la nueva frontera de la diseminación académica. El marco básico está representado por los servicios de comunicación en-línea que cada universidad provee a los miembros de su facultad, e incluye una página web institucional con información general y una lista de publicación adecuada para estudiantes y colegas. Sin embargo, un gran número de académicos han traspasado este límite al transformar sus páginas web personales en una presentación profunda de sus actividades investigativas pasadas y presentes. Pipa Norris ${ }^{74}$ quien ha estado muchos años al frente de la diseminación académica en-línea, presenta quizás el libre acceso más completo al trabajo personal de un/a académico/a. Su página web contiene material publicado, y sus libros e investigaciones en progreso. Sobre estos nos da sinopsis, marcos generales y borradores de capítulos, lo cual da como resultado la apertura de un proceso de colaboración. Pipa Norris se aprovecha de Google Books Search y ofrece un análisis de citas junto con una larga lista de libros que tienen referencias a sus trabajos, al mismo tiempo que vínculos directos a sus extractos disponibles en Google Books.

Peter J. Katzenstein ${ }^{75}$ ofrece una lista de publicaciones (organizada por fecha y tema) con algunos artículos libremente disponibles en formato PDF. También ofrece el currículo de sus cursos, incluye vínculos directos para acceder a módulos de e-learning (aprendizaje electrónico) o para subir material de sus estudiantes. Entre los artículos que libremente pueden ser descargados de su página web, hay algunos que pueden ser fácilmente compartidos con otra gente vía aplicaciones como Google Docs. Esta página web atestigua también el creciente uso de las llamadas aplicaciones web 2.0 que permite que se comparta, edite y actualice con más nivel, así como un uso más interactivo y creativo de cualquier material personal. La página web de Gary King, perteneciente a la misma tipología de sitios, ${ }^{76}$ provee un número impresionante de resúmenes, artículos, referencias de metadatos (incluye el King Dataverse Project $t^{7}$ para los estándares de citación de datos y métodos estadísticos), y materiales de cursos a través de un directorio organizado claramente y sencillo de navegar.

Otras páginas web individuales tienen un enfoque de investigación más definido. Ron Inglehart ${ }^{78}$ es el coordinador de un proyecto internacional sobre 
la evolución y la transformación de los valores y el comportamiento de la gente. Él administra una página web independiente (The World Values Survey) ${ }^{79}$ en compañía de una red de académicos de las ciencias sociales que trabajan bajo la World Values Survey Association. La información que ha sido recolectada en 80 países y dividida en cuatro olas, proporciona un panorama completo de la relación entre la cultura política y las instituciones democráticas. Su página web es muy sofisticada: junto con la descarga de archivos, también incluye análisis de datos en-línea relacionado con países específicos, sinopsis de materiales que la asociación ha publicado, así como trabajos y presentaciones disponibles en texto completo.

El Political Communication Lab ${ }^{80}$ localizado en el Departamento de Comunicación (Department of Communication) en la Universidad de Stanford y liderado por Shanto Iyengar, es otro sitio enfocado en actividades pedagógicas y de investigación. El Lab publica sus trabajos experimentales, documentos, material pedagógico, conferencias, lecturas y una gran colección de registros de multimedia relacionados con las elecciones en los EEUU: anuncios de campaña, posiciones sobre temas relevantes, comerciales, discursos, debates, entrevistas y contenido de los medios, todo disponible en-línea. Recientemente se ha incluido una colección de anuncios de la campaña presidencial de 2008 y un folleto titulado Media Politics: A Citizens Guide, junto con entrevistas, anuncios multimedia y más contenido relacionado con las elecciones presidenciales y estatales.

\section{Conectando a Platón}

Todas las revoluciones tecnológicas comienzan como nuevos medios para alcanzar viejos fines: material de lectura más accesible; lana más barata; transporte más rápido; o mejor iluminación. Sólo después de un uso más o menos prolongado se entiende que (usando la metáfora de Mcluhan), “el medio es el mensaje". Nuestra mente y nuestro cuerpo sufren una transformación radical, a la cual en retrospectiva le asignamos la etiqueta de una nueva era evolutiva. Unos pocos pero muy notables casos son tan dramáticos que ocurre un cambio de "marco-mental" (De Kerckhove, 1991). Esto es lo que probablemente ocurre con la penetración de Internet en nuestras rutinas diarias.

A pesar de esto, parecemos tener poca, si es que alguna, conciencia de este impacto y sus consecuencias, especialmente mientras más nos movemos hacia el epicentro del cambio: la transformación del conocimiento académico. Algunos estudios innovadores están abriendo finalmente nuevas perspectivas (Borgman, 2007; Nentwich, 2003), aunque la orientación principal sigue siendo escéptica y distante. Esta es un actitud bizarra, al considerar que como intelectuales profesionales pertenecemos al sector de la web que lleva a cabo el uso 
más intenso y complejo del nuevo lenguaje electrónico (Heimn, 1987). Aunque muchas personas pueden pasar más tiempo que un académico en frente de un computador, tienden a hacer actos simples y repetitivos. En cambio, los académicos a través de una variedad de funciones sofisticadas han entrado en una relación cuasi-simbiótica con el ciber-ambiente. Desde correos electrónicos hasta el procesamiento de textos o hasta la autoedición, desde leer libros o artículos en-línea y diseminar nuestros escritos a través de la web, estamos no solo modificando nuestros hábitos de trabajo, sino cambiando nuestros patrones de pensamiento. Desde la visionaria anticipación de Harnard (1991), la analogía con la revolución de Gutenberg es usada con frecuencia para indicar la magnitud de los cambios causados por la penetración de Internet en cada hogar. Sin embargo, la analogía tiene más profundidad que la extraordinaria masa de material cultural que con tanta facilidad está disponible para los cientos de millones de usuarios que usan la web. Hay más que un salto cuantitativo en la masa de conocimiento que está siendo diseminado a escala global. Hay dos cambios cualitativos que tienen que ser considerados para obtener un panorama completo del mar de cambio generado por el Gutenberg electrónico.

Elizabeth Einsenstein, en su estudio seminal sobre la imprenta como un agente de cambio, señaló que a través del primer siglo de la imprenta la gran ruptura con el pasado no consistió en la creación de una nueva literatura, sino en el hecho de que los lectores "podían por primera vez ver múltiples textos juntos y compararlos" (Duffy, 2000: 1). Este cambio metodológico trajo consigo una nueva mentalidad abierta y deseosa de examinar y discutir los varios matices de un argumento complejo. Según Einsenstein este es el hilo común que une al renacimiento, la reforma protestante y la revolución científica, los tres grandes acontecimientos en la estela de la imprenta. De esta manera la historia de la publicación de libros se convirtió en la cuenca para la historia más general de las ideas. Todavía no hemos visto ni reconocido los frutos del advenimiento de la nueva ciencia electrónica en nuestra civilización (Jankowski, 2007; Schroeder and Fry, 2007). Sin embargo, es posible que tengamos que prepararnos para una cosecha trascendental.

Un segundo punto de unión entre Gutenberg y la web, es el hecho de que "la imprenta tuvo su mayor impacto científico en aquellos que trabajaban fuera de las universidades, y no tanto en los académicos que estaban en ellas. Las universidades no fueron rápidos entusiastas del libro impreso" (Willinsky, 2005: 192). Sería injusto decir que las universidades no están jugando un rol principal en el uso y la promoción de Internet como un agente de cambio cultural. Sin embargo, un extraordinario (y poco conocido) componente de la revolución de la web consiste en los millones de amateurs e intelectuales que se están autopromocionando, y migrando todos hacia El Dorado del internet como la nueva 
frontera de oportunidades de educación, inspiración, invención e interacción. Esta apertura de la fortaleza de la educación superior está destinada a rediseñar el mapa cultural y científico dentro del hemisferio occidental, y aún más, en su relación con las naciones en vía de desarrollo y sus poblaciones densamente interconectadas. ${ }^{81}$

En el final (o en el nuevo comienzo) de la última ola tecnológica, sus más preciosos y originales frutos parecen pesar directamente sobre los cambios en el comportamiento humano o más específicamente en el "comportamiento relacionado con la información" (Borgman, 2003). Después de haber pasado 50 años experimentando con el desarrollo de la Inteligencia Artificial, quizá estemos acercándonos a la meta a través de un camino indirecto e inesperado. En vez de ser el resultado de investigaciones de laboratorio y de robótica, una nueva inteligencia parece estarse gestando desde la convergencia e integración del entendimiento humano a través de Internet. De cierta manera, todos estamos contribuyendo y participando en el nacimiento de una "web inteligente" (Alesso y Smith, 2006). Wikipedia es un ejemplo sin precedentes de cuán rápido la combinación de conocimientos y el acceso libre pueden mezclarse para crear nuevos productos culturales que inmediatamente se convierten en un estándar y en un sine qua non del mundo literario (Shirki, 2008; Sunstein, 2006; Tapscott and Williarns, 2006).

En su estudio pionero sobre la mente griega, Eric Havelock (1963), explicó que la grandísima influencia de Platón en el pensamiento occidental, se debía al hecho de que sus teorías aparecieron en un momento cuando el lenguaje escrito estaba reemplazando a la tradición oral como la forma dominante para el desarrollo de conceptos. Los diálogos platónicos se convirtieron en la primera y más influyente expresión del lenguaje escrito como un nuevo método de pensamiento. Nosotros probablemente seremos testigos del advenimiento de un nuevo Platón, un Platón colectivo y conectado, cuyo "marco-mental" sustituirá al antiguo que hemos usado durante los últimos 500 años. Al presentar un breve panorama de los recursos electrónicos disponibles para la investigación e interacción académica a nivel global, apenas hemos comenzado a cartografiar un nuevo viaje hacia el conocimiento, al cual la ciencia política puede hacer grandes contribuciones. A los entusiastas y escépticos, "Bienvenidos abordo". Y como Edward R. Murrow diría si estuviera vivo, "Buenos días y buena suerte". 


\section{Notas}

1 Frank Rhodes Presidente Emérito, Cornell University citado en Duderstadt (2001:56)

2 Esta mención superficial se refería al rol de los archivos electrónicos en facilitar la adquisición de datos empíricos (Hochschild, 2005: 323). Recientemente Robert Axelrod (2008:7), en su discurso presidencial enfatizó: "el nuevo campo de instituciones con base en la web... como un dominio particularmente prometedor para las exportaciones de ciencia política... especialmente las instituciones que usen en gran escala las formas de abajo-hacia-arriba para su organización y manejo".

3 El portal IPSA de la International Political Science Association, es una publicación en-línea inaugurada en el veinteavo congreso mundial de IPSA en Fukuoka, Japón. El portal IPSA tiene como objetivo fomentar la investigación de ciencia política en-línea al seleccionar, reseñar y evaluar las mejores páginas web que proveen información, materiales y fuentes para la investigación académica. El portal (www.ipsaportal.net) ofrece acceso gratis a evaluaciones de las 300 mejores páginas web sobre ciencia política, y una versión impresa se distribuye en los congresos mundiales de IPSA.

4 Contrastar el factor "Amazoogle" (el cual es "el enorme impacto de los gigantes de la información en la manera como los académicos y los estudiantes buscan y usan la información”) es una de las metas principales del plan estratégico 2006-09 de la biblioteca de la Universidad de Columbia (Columbia University Library) en su empuje por diseñar "servicios para la era del auto-servicio".

5 Para un visión exacta del estado del arte ver Mark Ware Consulting (2006:7) que reporta que "hay aproximadamente 23,000 revistas académicas reseñadas por pares, que colectivamente publican 1.4 millones de artículos al año. Un subgrupo importante son las 8,700 revistas incluidas en la ISI Journal Citation Database, de la cuales 5,900 están en la edición de ciencias, 1,700 en las ciencias sociales y 1,130 en las ediciones de artes y humanidades, y que colectivamente publican 1 millón de artículos anuales. Este subgrupo es importante porque contiene las revistas más citadas, lo que de acuerdo a esta medida, conforma la literatura medular.

6 Las fusiones en la industria editorial se están acelerando tanto que es difícil mantenerse al día. Willinsky (2005: 18) citando una fuente de 2003 registra que Elsevier con 1,800 revistas, Taylor y Francis con 1,000 y Springer con más de 500 son el 60 por ciento del total de materiales indexados en la ISI Web of Science. Según Mark Ware Consulting (2006:11), en los siguientes tres años, la concentración ha avanzado fuertemente ya que "la distribución de revistas por editorial es bastante sesgada, con dos editoriales (Elsevier y Springer) teniendo alrededor de 2,000 revistas cada una. El 2 por ciento más alto (11 editoriales) produce más del 70 por ciento de revistas en este grupo, es decir, un 35 por ciento del total de revistas": Un año después, "en febrero del 2007, John Wiley e Hijos completó la adquisición de Blackweel Publishing (Holdings) Ltd. Estas compañías fusionadas publican aproximadamente 1,250 revistas académicas y cientos de libros académicos cada año, lo que los hace la tercera editorial de revistas académicas más grande del mundo (después de Elsevier y Springer)."

7 Reed Elsevier ha accedido a "dejar que sus autores carguen las versiones finales de sus trabajos a archivos de acceso libre y su portal Science Direct provee acceso gratuito a información bibliográfica y resúmenes de sus mil ochocientas revistas." (Willinsky, 2005: 28).

8 Citado en Hochschild (2005: 323) Compare esto con los poco satisfactorios resultados reportados hace sólo 10 años atrás por Shaw et al (1996: 501:4) con respecto a sus hallazgos en documentos presidenciales: "Los recursos en-línea seguramente acelerarán y expandirán las dimensiones de la investigación y de la recolección de información; sin embargo, estos esfuerzos relativamente mecánicos todavía no han reemplazado el antiguo trabajo de detective aprendido en el pasado fuera de línea en la librería material".

9 ipsaportal.net en sus cuatro años de actividad ha monitoreado más de 1,000 páginas web, para seleccionar 300 de las más autorizadas, estables y generosas en cuanto a acceso libre. La selección se lleva a cabo según políticas muy detalladas que reflejan los tres criterios principales: contenido, acceso y manejo.

10 El Librarians' Index to the Internet (http://lii.org, $/$ ) es un esfuerzo extraordinario para monitorear el universo en expansión de la internet, proveyendo de vínculos a sitios de libre acceso, que fueron seleccionados con criterios rigurosos y transparentes. Es un directorio de búsqueda de más de 20,000 recursos de internet seleccionados y evaluados por bibliotecarios. 
11 El Intute: Social Sciences (http:/ /www.intute.ac.uk/socialsciences/), con más de 30,000 fuentes en la web, es tanto un catálogo como un motor de búsqueda que cubre los recursos en Internet en los campos de educación e investigación de las ciencias sociales, con algunas extensiones en negocios, derecho, deportes y turismo.

12 Para obtener una medida aproximada de la expansión del mundo de las bibliotecas digitales durante la última década, uno puede buscar en Amazon las publicaciones con "biblioteca digital" o "bibliotecas digitales" en el título y nos mostrará 600 títulos, el doble de la misma búsqueda hace dos años. Para las tendencias y visiones claves que lideran este proceso hay que comparar el innovador trabajo de Dowler (1997) con el profundo análisis del estado del arte, de Brown et al. (2007).

13 URL: http:,/ /www.loc. gov.

14 Somos conscientes de que las cifras sobre catálogos, colecciones y varias bases de datos son muy tentativas y corren el riesgo de convertirse en obsoletas muy rápidamente. Sin embargo, ayudan al lector principiante a que obtenga una idea mejor del fenómeno que estamos describiendo.

15 URL: http://www.theeuropeanlibrary.org

16 Este proceso de integración y convergencia también opera en un nivel meta-organizacional. El desarrollo de catálogos colectivos (Union Catalogs) es el resultado del proceso de estandarización de los metadatos y de la mayor interoperabilidad de diferentes sistemas de indexación, así como un indicador de la penetración del proceso de globalización en la web profunda. El más grande de semejantes catálogos es Worldcat (www.worldcat.org), desarrollado por el Online Computer Library Center, y que provee acceso (restringido a las bibliotecas suscritas) a más de 100 millones de registros.

17 Clifford Lynch (2003:5) hace una distinción crítica entre "colecciones digitales como cosas cercanas a contenido en bruto... y bibliotecas digitales como los sistemas que hacen que las colecciones adquieran vida haciéndolas útiles y accesibles".

18 URL: http://www.memory.loc.gov/ammem/index.html

19 URL: http://thomas.loc.goc

20 URL: http://www.loc.gov/chroniclingamerica/index.html

21 URL: http://quod.lib.umich.edu/m/moargp

22 URL: http://gallica.bnf.fr

23 URL: http://gallica.bnf.fr/dicos/dictlisteK.htm.

24 URL: http://www.ulib.org

25 URL: http://www.ulib.org/ULIBAboutUs.htm.

26 El Proyecto Gutenberg, fundado en 1971 por Michael Hart (http://www.gutenberg.org), representa el primer proyecto de digitalización y la primera colección gratuita de libros electrónicos. En su creciente archivo tiene disponibles 25,000 ubicados (hosted) en los EEUU y 100,000 en otros países. Todos sus libros-electrónicos están libres de copyright y se pueden descargar en formatos de texto completo. Cuentan con una comunidad global que está trabajando para mantener la iniciativa.

27 URL: http//books.google.com/googlebooks/partners.html

28 URL: http//books.google.com

29 Algunas compañías editoriales y grupos de escritores han criticado el que el proyecto haya incluido retazos de material con copyright, infringiendo así la regulación existente. Sin embargo, Google, mediante una variedad de limitaciones de acceso y medidas de seguridad, algunas basadas en rastreo de los usuarios, limita el 
número de páginas que se pueden ver y busca prevenir la impresión de páginas y la copia de texto de material protegido por copyright.

30 Según un censo reciente (Mark Ware Counsulting, 2006: 8) en el 2005, "90 por ciento de todas las revistas estaban en-línea, con el 93 por ciento siendo de STM (científicas, técnicas y médicas) y 84 por ciento de las artes y humanidades." Debido a problemas financieros, muchas bibliotecas están descontinuando sus suscripciones de papel, con las respectivas consecuencias en la pluralidad y la estructura de las compañías editoriales.

$31 \mathrm{El}$ ascendente costo de suscripciones a revistas, aunque sea la fuerza principal en la reorganización digital de las bibliotecas, ha provocado fuertes controversias sobre sus reales dimensiones y consecuencias (Mark Ware Consulting, 2006: 12-13; Willinsky, 2005: I 7-20).

32 Por ejemplo, la biblioteca de la universidad de Harvard ha decidido recientemente "reducir el número de suscripciones a revistas de Elsevier" (Willinsky,2006:25) para obtener de nuevo el control "sobre las colecciones [de la biblioteca]". Para una estrategia completa para contrastar los "modelos actuales de publicación académica que no son económicamente sostenibles", ver el programa y las acciones de las bibliotecas de la Universidad de California en http://libraries.universityofcalifornia.edu/scholarly.

33 La colección profesional más completa de resúmenes de artículos sobre ciencia política la tiene el International Political Science Abstracts. Provee más de 100,000 de tales resúmenes de artículos publicados a nivel mundial desde 1989 hasta el presente en revistas y anuarios. Se necesita, sin embargo, una suscripción institucional o particular. Comenzó en 1951 como una revista impresa y hoy en día cubre artículos de más de 900 revistas.

34 URL: http://www.JSTOR.org

35 Un vínculo permanente es un URL, resultado de una búsqueda. Suele ser usado para mejorar el sistema de vínculos entre páginas web soportadas en bases de datos, o para dar más estabilidad al proceso de citación de fuentes en la web.

36 URL: http://muse.jhu.edu

37 EL proyecto SciElo (http://www.scielo.br) es el producto de una alianza entre la Fundacao de Amparo à Pesquisa do Estado de Sao Paulo (FAPESP o La Fundación de Ciencias del Estado de Sao Paulo) y el Latin America and Caribean Center on Health Sciences Information (BIREME). Desde el 2002 el proyecto ha recibido también apoyo del Conselho Nacional de Desenvolvimento Científico e Tecnológico (CNPq).

38 URL: http://www.cairn.info

39 Según Dunleavy et al (2006:4), "El desarrollo temprano de los sistemas de IT en los años 30, no hizo más que indexar (al principio) grandes y (más tarde) vastas cantidades de documentación en papel. En los ochentas con el desarrollo de bases de datos estructuradas y relacionales, y luego en los noventas con el importante avance al almacenamiento electrónico y a la capacidad de acceso completos, se hizo el cambio fundamental de este patrón. El advenimiento de la web como el camino universal al conocimiento completó la transformación”.

40 URL: http://www.naa.gov.au

41 URL: $\underline{\text { http: //www.archives.gov }}$

42 URL: http://www.archives.gov/research/arc.

43 URL: http://www.gpo.gov

44 URL: http://www.digitalvaults.org

45 En el 2007, NARA inauguró un programa de digitalización, en alianza con la Footnote Company, para digitalizar 4.5 millones de documentos disponibles en microfilmes. Aunque actualmente sólo Footnote puede explotar este material (parcialmente libre de cargos), éste será reintroducido en cinco años a las posesiones de NARA. Footnote ha adoptado la misma estrategia de marketing que Google: ayuda financiera vs contenido. 
46 URL: http://www.icpsr.umich.edu

47 URL: http:// www.icpsr.umich.edu/ICPSR/citacions/index.html

48 URL: http://www.nsd.uib.no/cessda/home.html

49 URL: http://www.gesis.org/en/Za

50 URL: http://cdsp.sciences-po.fr

51 URL: http://www.europeansocialsurvey.org

52 URL:http://www.gesis.org/en/data_service/eurobarometer/standard_eb/index.htm

53 URL: http://www.issp.org

54 URL: http://www.europeanvalues.nl

55 URL: http://www.ipu.org

56 URL: http://www.ipu.org/iss-e/issues.htm

57 URL: http://www.ipu.org/parlit-e/parlitsearch.asp

58 URL: http://www.ipu.org/parline-e/parlinesearch.asp

59 URL: http://www.ipu.org/bdf-e/BDFsearch.asp

60 URL: http://arxiv.org

61 URL: http://www.arl.org/sparc

62 URL: http://www.ssrn.com

63 URL: http://spire.sciences-po.fr/spire

64 URL: http://bibliotheque.sciences-po-fr

65 También contiene economía, historia, geografía, derecho, relaciones internacionales y sociología, con más de 900,000 libros, 200,000 artículos indexados y 18,000 archivos de prensa de 1946 al 2005, de acceso gratis como resúmenes.

66 URL: http://www.lse.ac.uk/library

67 URL: http://eprints.lse.ac.uk

68 URL: http://www.politicalscience.org

69 Estas incluyen: la International Studies Association, la Midwest Political Science Association, la New England Political Science Association, la Northeastern Political Science Association, la Political Studies Association (UK), la Southwestern Political Science Association, la Southern Political Science Association y la Western Political Science Association.

70 URL: http://www.aspanet.org

71 URL: http://www. aspanet.org/content_2936.cfm

72 URL: http://www.oiaster.org 
73 URL: http://www.openarchive.org/pmh

74 URL: http://www.pippanorris.com

75 URL: http://falcon.arts.cornel.edu/Govt/faculty/katzenstein/index.html

76 URL: http://gking.harvad.edu/homepage.html

77 URL: http://thedata.org

78 URL: http://polisci.lsa.umich.edu/faculty/ringlehart.html

79 URL: http:// www.worlvaluessurvey.org

80 URL: http://pcl.stanford.edu

81 Según un reporte hecho por el China Internet Network Information Center (2008: 9), "hasta diciembre de 2007 el número total de ciudadanos de la net en China se había incrementado a 210 millones, con un fuerte aumento de 73 millones en el año de 2007, a una tasa de crecimiento anual del 53.3 por ciento. Con respecto a los métodos de acceso, los usuarios de banda ancha son 163 millones y desde el celular 50.4 millones, ambos con un crecimiento acelerado".

\section{Referencias}

-Alesso, H.P. and Smith, C.F. (2006). Thinking on the Web: Berners-Lee, Gödel and Turing. Hoboken, NJ: Wiley.

-Axelrod, R. (2008). "Political Science and Beyond: Presidential Address to the American Political Science Association", Perspectives on Politics 6 (1): 3-9.

-Babini, D. and Smart, P. (2006). "Using Digital Libraries to Provide Online Access to Social Science Journals in Latin America", Learned Publishing 19(2): $107-13$.

-Benkler, Y (2006). The Wealth of Networks: How Social Production Transforms Markets and Freedom, New Haven, CT: Yale University Press.

-Bergman, M.K. (2001). The Deep Web: Surfacing Hidden Value, URL: http:// www.brightplanet.com/images/stories/pdf/deepwebwhitepaper.pdf.BrightPlanet.

-Besser, H. (2002). The Next Stage: Moving from Isolated Digital Collections to Interoperable Digital Libraries", First Monday 7(6), URL:http//www. firstmonday.org/issues/issueT_6/besser. 
-Bohlin, I. (2004). "Communication Regimes in Competition: The Current Transition in Scholarly Communication Seen through the Lens of the Sociology of Technology", Social Studies of Science 34: 365-91.

-Bolter, J.D. (2001). Writing Space: Computers, Hypertext, and the Remediation of Print. Philadelphia, PA: Lawrence Erlbaum Associates.

-Bond, C.S., Fevyer, D. and Pitt, C. (2006). "Learning to Use the Internet as a Study Tool: A Review of Available Resources and Exploration bf Students' Priorities," Health Information and Libraries Journal 23: 189-96.

-Borgman, C.L. (2003). From Gutenberg to the Global Information Infrastructure. Cambridge, MA: MIT Press.

-Borgman C.L. (2007). Scholarship in the Digital Age: Information, Infrastructure, and the Internet. Cambridge, MA: MIT Press.

-Brown, L., Griffiths, R. and Rascoff, M. (2007). "University Publishing in a Digital Age", Ithaca Report. Ithaka.org.

-Burnham, P., Grant, W. and Gilland K. (2008). Research Methods in Politics. Basing Stoke: Palgrave Macmillan.

-Castells, M. (1996). The Rise of the Network Society. Oxford: Blackwell.

-Castells, M. (2000). "Toward a Sociology of the Network Society", Contemporary Sociology 29 (5): 693-9.

-China Internet Network Information Center (2008). Statistical Survey Report on the Internet Development in China, URL: http:/ / www.cnnic.net.cn/en/index0O/ index.htm.

-Choucri, N. (2000). "Cyber Politics in International Relations", International Political Science Review 21(3): 243-63.

-Cohen, D.J. and Rosenzweig, R. (2006). Digital History: A Guide to Gathering, Preserving, and Presenting the Past on the Web. Philadelphia: University of Pennsylvania Press. 
-Columbia University Library (2006). "Columbia University Library Strategic Plan 2006-2009,” URL: www.columbia.edu/cu/lweb/img,/assets/6675/ strategicplan_2002-2009.pdf. New York: Columbia University.

-Courant, P.N. (2006). "Scholarship and Academic Libraries (and their Kin) in the World of Google", First Monday 11(8), URL: http://www.firstmonday. org/ISSUES/issue11_8/courant/index.html.

-Deibert, R.J. (1998). "Virtual Resources: International Relations Research Resources on the Web", International Organization 52(1): 211-21.

-De Kerckhove, D. (1991). Brainframes: Technology, Mind and Business. Utrecht: Bosch \& Keuning.

-DiMaggio, P., Hargittai, E., Neuman, W.R. and Robinson, J.P.(2001). "The Social Implication of the Internet", Annual Review of Sociology 71: 307-36.

-Dowler, L . (1997). Gateways to Knowledge: The Role of Academic Libraries in Teaching, Learning and Research. Cambridge, MA: MIT Press.

-Duderstadt, J. (2001). "The Future of the University in the Digital Age", Proceedings of the American Philosophical Society 145: 54-72

-Duffy, S.E. (2000). “The Unacknowledged Revolution”, URL: http:// www.h-net.org/reviews/showrev.cgi?path $=24899962821867$.

-Dunleavy, P., Margetts, H., Bastow, S. and Tinkler, J. (2006). Digital Era Governance: IT Corporations, the State and E-government. Oxford: Oxford University Press.

-Dunleavy, P. et al. (2008). “Is Duverger's Law Based on a Mistake?” Paper presented at the Political Studies Association Annual Conference, 2008.

-Eisenstein, E.L. (1979). The Printing Press as an Agent of Change: Communications and Cultural Transformations in Early-Modern Europe. Cambridge and New York: Cambridge University.

-Giles, M. (1996). "From Gutenberg to Gigabytes: Scholarly Communication in the Age of Cyberspace", Journal of Politics 1 (58): 613-26. 
-Harnad, S. (1991). "Post-Gutenberg Galaxy: The Fourth Revolution in the Means of Production of Knowledge", Public-Access Computer Systems Review 2(1): 39-53.

-Havelock, E. (1963). Preface to Plato. Cambridge, MA: Belknap Press.

-Heim, M. (1987). Electric Language. London: Yale University Press.

-Hillesund, T. (2007). "Reading Books in the Digital Age Subsequent to Amazon, Google and the Long Tail", First Monday 12 (9), URL: http://www. firstmonday.org/issues/issue 6-10/ hillesund.

-Hochschild, J.L. (2005). "APSA Presidents Reflect on Political Science: Who Knows What, When, and How?” Perspectives on Politics 3(2): 309-34.

-Jankowski, N.W. (2007). "Exploring E-science: An Introduction”, Journal of Computer-Mediated Communication 12: 549-62.

-Jeanneney J-N. (2007). Google and the Myth of Universal Knowledge: A View from Europe. Chicago, IL: University of Chicago Press.

-Kaase, M. (2000). "Political Science and the Internet", International Political Science Review 21 (3): 265-82.

-Kurzweil, R. (1992). "The End of the Book", Library Journal, February 15: 140-1.

-Landow, G.P. (1997). Hypertext 2.0: The Convergence of Contemporary Literary Theory and Technology, Baltimore, MD: Johns Hopkins University Press.

-Landow, G.P. (2006), Hypertext 3.0: Critical Theory and New Media in an Era of Globalization. Baltimore, MD: Johns Hopkins University Press.

-Laponce, J. (2001), "Politics and the Law of Babel", Social Science Information 40: 179-94.

-Lazer, V. and Mayer-Schönberger, D., eds (2007). Governance and Information Technology: From Electronic Government to Information Government. Cambridge, MA: MIT Press. 
-Lessig, L. (2004). Free Culture: How Big Media Uses Technology and the Law to Lock Down Culture. New York: Penguin Books.

-Lynch, C. (2003). "Institutional Repositories: Essential Infrastructure for Scholarship in the Digital Age”, ARL226: 1-7, URL: http:/www.arl.org,/ resources/pubs/br/br226/br226ir.shtml.

-Lynch, C. and Lippincott, J.K. (2005). "Institutional Repository Development in the United States as of Early 2005”, D-Lib Magazine: 1-9. URL: http:/ / www.dlib.org/dlib/september05//lynch/09lynch.html.

-McLuhan, M. (1962). The Gutenberg Galaxy: The Making of Typographic Man. Toronto: University of Toronto Press.

-Mark Ware Consulting (2006). "Scientific Publishing in Transition: An Overview of Current Developments", URL: www.markwareconsulting.com.

-Meyrowitz, J. (1985). No Sense of Place: The Impact of Electronic Media on Social Behavior. Oxford: Oxford University Press.

-Nentwich, M. (2003). Cyberscience: Research in the Age of the Internet. Vienna: Austrian Academy of Sciences Press.

-Nentwich, M. (2008) "Political Science on the Web: Prospects and Challenge”, European Political Science, 7: 220-29.

-Nunberg, G. (1993). "The Place of Books in the Age of Electronic Reproduction", Representations 42: 13-37.

-Quinn, B.A. (2007). "Web-Based Reference Resources for the Social Sciences.”, URL: http://esr.lib.ttu.edu/lib_fac_research/3.

-Robinson, A.M and Schlegl, K (2005). "Student Use of the Internet for Research Projects: A Problem? Our Problem? What Can We Do About It?", PS, April: 311-15

-Rosenzweig, R. (2001). "The Road to Xanadu: Public and Private Pathways on the History Web", Journal of American History 88: 548-7. 
-Schonfeld, R. C. (2003). JSTOR: A History. Princeton, NJ: Princeton University Press.

-Schroeder, R. and Fry, J. (2007). "Social Science Approaches to E-science: Framing an Agenda", Journal of Computer-Mediated Communication 12: 563-82.

-Selcher, W.A. (2005). "Use of Internet Sources in International Studies Teaching and Research", International Studies Perspectives 6: 174-89

-Shaw, G.M., Shapiro, R.Y and Jacobs, L.R. (1996). "Searching Presidential Documents On-Line: Advantages and Limitations", PS: Political Science and Politics 29: 501-4.

-Shirky, C. (2008). Here Comes Everybody: The Power of Organizing Without Organizations. New York: Penguin.

-Spang, B .N. (1997). "Political Science and Global Computer Networks", European Journal of Political Research 31: 35-45.

-Sunstein, C. (2006). Infotopia: How Many Minds Produce Knowledge. New York: Oxford University Press.

-Tapscott, D. and Williams, A.D. (2006). Wikinomics: How Mass Collaboration Changing Everything. New York: Portfolio.

-Taylor, J. (2001). "JSTOR: An Electronic Archive from 1665", Notes and Records of the Royal Society of London 55: 179-81.

-Thatcher, S.G. (2007). "The Future of Scholarly Book Publishing in Political Theory", PS Online, January: 129-32, URL: www.apsanet.org.

-Thompson, J.B. (2005). Books in the Digital Age: The Transformation of Academic and Higher Education Publishing in Britain and the United States. Cambridge: Polity.

-Verba, S. (2004). "A Letter from Sydney Verba", Library Notes, Harvard University, Number 1317, URL: http://hul.harvard.edu/publications/hul_notes_1317/verba.html. 
-Vise, D. and Malseed, M . (2005). The Google Story. New York: Bentam Dell.

-Walker, M . (1998). "Netting the Future: International Relations Online", International Affairs 74 (2):409-13.

-Willinsky, J. (2005). The Access Principle: The Case for Open Access to Research and Scholarship. Cambridge, MA: MIT Press.

-Wilson, I.E. (2007). "Introduction", in J-N. Jeanneney, Google and thy Myth of Universal Knowledge, A View from Europe. Chicago, IL: University of Chicago Press.

-Wright, A. (2004). "In search of the Deep Web", Salon, May 23, URL: http://dir.salon.corn/story/tech/featnre /2004/03/09/deep_web.

\section{Notas biográficas}

Mauro Calise es profesor de ciencia política en la Universidad Federico II de Nápoles y presidente de la Asociación Italiana de Ciencia Política (2008-10). Ha publicado libros, artículos y columnas de periódicos en varias áreas como teoría del estado, partidos políticos, élites ejecutivas, comunicación política y análisis de conceptos. Sus intereses actuales se centran en la cultura y la epistemología de la web. Es coautor de Hyperpolitics: An Interactive Dictionary of Political Science, junto con Theodore J. Lowi. University of Chicago Press, E-mail: calise@unina.it

Rosanna de Rosa es una profesora asistente en el Departamento de Sociología en la Universidad Federico II de Nápoles, en donde enseña Comunicación Política. Sus publicaciones se centran principalmente en analizar el impacto de nuevas tecnologías en la política. Es editora asistente del Ipsaportal.net, el portal web para fuentes electrónicas, de la Asociación Internacional de Ciencia Política (Internacional Political Science Association Web Portal for Electronic Sources). E-mail:rderosa@unina.it 